\title{
Application of Comprehensive AGC System for Aluminum Twin-Stand Cold Rolling Mill
}

\author{
Fei Zhang ${ }^{1,2}$, Xiang Wang ${ }^{3}$, Shengyue Zong ${ }^{1}$, Zhi Ling ${ }^{1}$ and Hongping Pei ${ }^{4}$ \\ ${ }^{1}$ Institute of Engineering Technology, University of Science and Technology \\ Beijing, Beijing, 100083, China \\ ${ }^{2}$ School of Electrical, Computer \& Telecommunications Engineering, University \\ of Wollongong, NSW 2522, Australia \\ ${ }^{3}$ Material Industry \& Development Department, Aerospace Research Institute of \\ Material \& Processing Technology, Beijing, 100076, China \\ ${ }^{4}$ Research and Design Institute of USTB Co., Ltd, Beijing, 100083, China \\ zhfeicn@gmail.com
}

\begin{abstract}
The design and implementation of the automatic gauge control (AGC) system of an aluminum twin-stand cold rolling mill are discussed. Integration of the thickness control with feedforward AGC, gaugemeter AGC, monitor AGC and gap compensations resulted in a fully coordinated gauge control system, which provides the ability to make quick and accurate modifications to both control loops and tuning constants, and contributes to the improvement of gauge accuracy and stable rolling. Production data display that the ratio of the thickness deviation falling within $\pm 1 \%$ of the target thickness increased from $94.6 \%$ to $98.4 \%$, which reveals that this gauge control system with the eccentricity and oil film compensation is superior to the conventional gauge control system in the strip gauge control accuracy. For the old production lines, the application of this system does not need new equipment, and therefore it is suitable for the revamping and upgrading of the old system.
\end{abstract}

Keywords: automatic gauge control, eccentricity compensation, oil film compensation, twin-stand mill, cold rolling mill

\section{Introduction}

Aluminum cold rolling is a rolling process to reduce the thickness with a further objective of improving the strength, surface finish and formability of the stock by conducting the process of rolling at the room temperature [1]. Aluminum alloys can be cold rolled down to thicknesses of around $0.05 \mathrm{~mm}$. Pure (low-alloy) aluminum can be cold rolled into foil as thin as $0.0025 \mathrm{~mm}$. Strip destined for cold rolling to thicknesses under about $1 \mathrm{~mm}$ is usually hot rolled to about 3-6 $\mathrm{mm}$ before cold rolling begins.

The twin-stand Aluminum cold rolling mill under consideration is shown diagrammatically in Figure 1. The incoming strip is fed from the decoiler between the rolls of the stand 1, which exerts sufficient pressure to bring about plastic flow of the metal and reduction of thickness. The strip then enters the stand 2, where it is further reduced to its final thickness, and coiled on to the coiler. The metal strip is under tension at all points. The thickness of the product and the tension of the metal between the two stands may be controlled by adjusting the roll gaps and the speed difference between the two sets of rolls. In the steady state, these parameters are chosen to achieve the desired reduction and tension while approximately equalizing the roll forces exerted by the two stands. This minimizes roll bending, and thus assists in rolling strip of nearly uniform thickness [2]. 


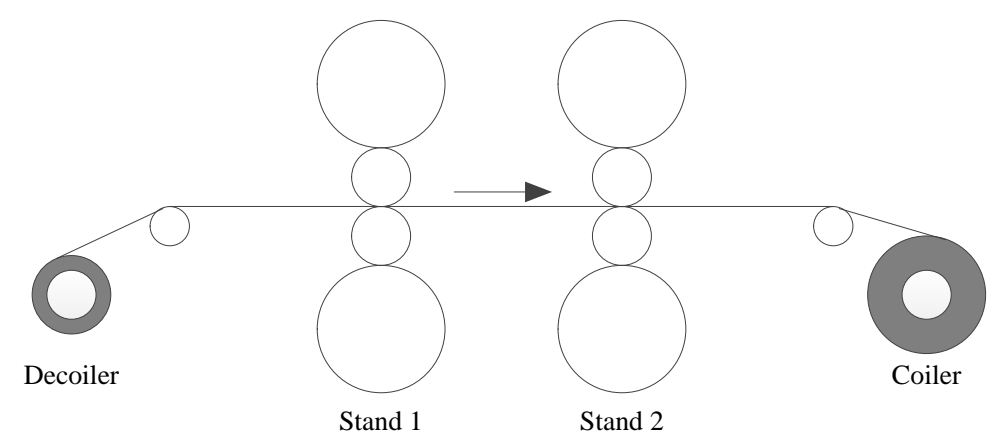

Figure 1. Schematic Twin-Stand Mill

During rolling, the mill is subject to the disturbances which affect both product thickness and interstand tension. The first of these is the variation in entry strip thickness. The incoming strip has previously been hot rolled, and has some pattern of thickness variation characteristic of the hot mill. Secondly, the mill is threaded at low speed, and accelerated to its working speed after the strip enters the second stand. A similar process of deceleration is followed on the runout of the end of a coil. Both thickness and tension are strongly affected by rolling speed, thickness increasing by as much as 50 per cent as the mill slows, and tension increasing drastically [2]. This may be ascribed to changes in the coefficient of rolling friction in each stand, which is a dominant factor in the rolling process. In addition, rolling theory is at best an approximation, and much of the input data used to predict steady-state operating conditions is also approximate.

As the work hardening increases, it takes more power to roll the sheet thinner. Beyond a certain degree of hardness, the metal may crack if it is rolled again [3]. This imposes practical limits on the amount of cold rolled thickness reduction that can be achieved in an uninterrupted series of passes. When further thickness reduction is necessary, the sheet must be annealed as described above to soften the metal for further cold rolling.

Although the sheet enters the mill "cold", at room temperature, the friction and pressure of rolling may raise its temperature to about $80^{\circ} \mathrm{C}$ or more. This excess heat must be removed by an appropriate coolant/lubricant.

\section{Mathematical Model}

Thickness precision is one of the most important quality indexes in strip rolling process [4-5]. In the rolling of metals, especially the final cold rolling of sheet materials, the variation of thickness along the length of the strip must be controlled within very tight tolerances [6].

\subsection{Force Equation}

The well-known Sims' model is presented widely in the literature as being useful for control development [7]. In Sims' model, the specific roll force is represented as

$$
P=W k k_{t} Q_{p} L
$$

where $W$ is the strip width, $k$ is the resistance to deformation, $k_{t}$ is the effect of tensions, $Q_{p}$ is the roll force function, and $L$ is the projected contact length.

Referring to Figure 2, which approximately represents the strip in the roll bite area, the incoming strip is of thickness $H$ at its centerline and is moving toward the roll bite with speed $v_{i n}$. The strip exits the roll bite with thickness $h$ at its centerline and with speed $v_{\text {out }}[8-10]$. 


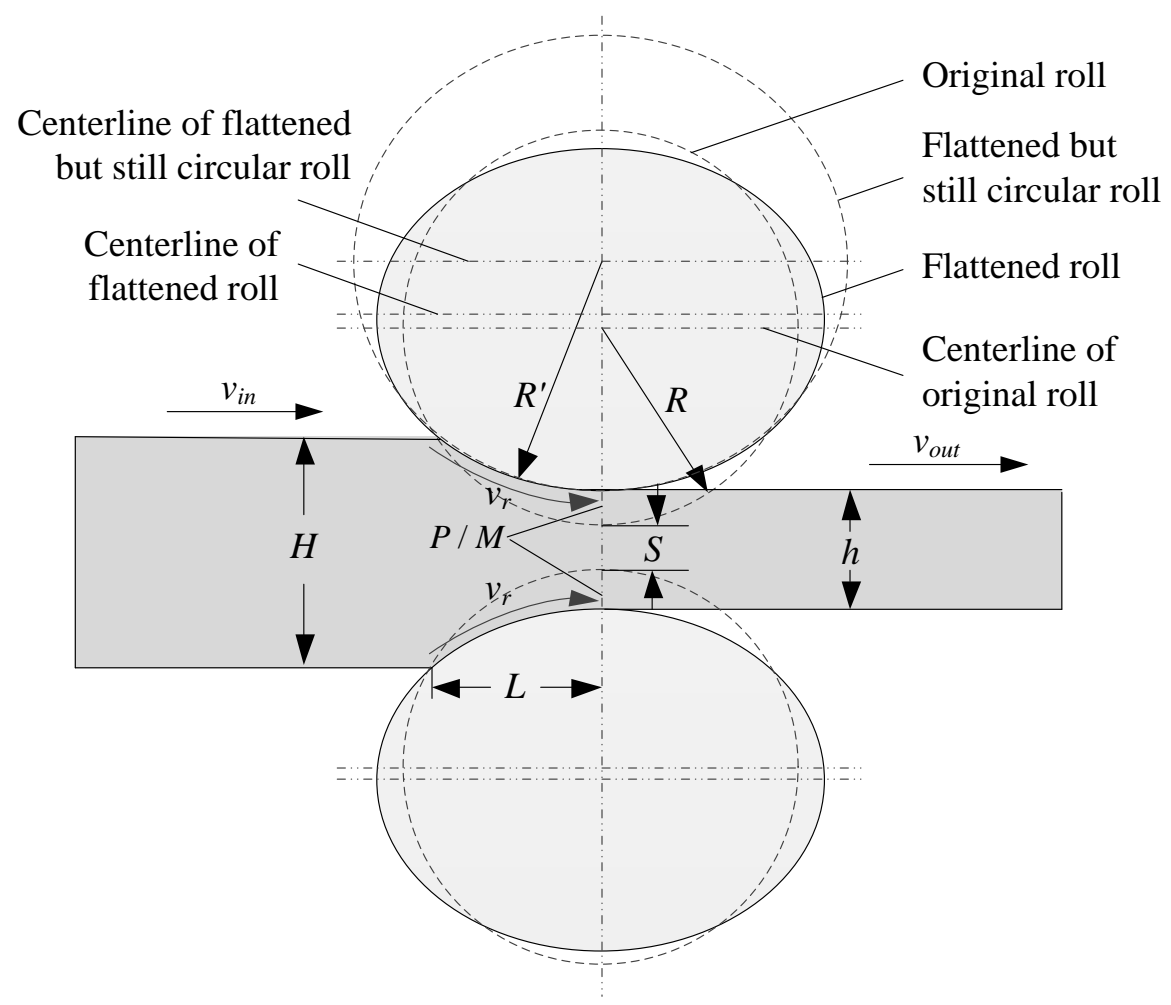

Figure 2. Roll Bite Area

The projected contact length is expressed as,

$$
L=\sqrt{R^{\prime}(H-h)}
$$

The flattened but still circular roll radius is obtainable from Hitchcock's relation [11],

$$
R^{\prime}=R\left[1+\frac{16\left(1-v^{2}\right)}{\pi E(H-h)}\right]
$$

where $R$ is the original radius of the work roll, and $v$ is the Poisson's ratio, and $E$ is the Young's modulus for the work roll.

\subsection{Gaugemeter Equation}

A typical and basic modeling task is associated with setting up the roll gaps in a mill. Because the large deformation force $P$ required to reduce the strip thickness from entry thickness $H$ to exit thickness $h$ causes the stand frame holding the rolls to stretch, and mill rolls to bend and flatten. The result is the exit thickness as a function of force $P$. In simplified form this can be expressed as [12]:

$$
h=S+f(P)
$$

where $S$ is the unloaded roll gap, and the term $f(P)$ is the mill stretch.

As shown in Figure 2, the normally used simplified thickness model of gaugemeter equation or spring equation has the following form [13],

$$
h=S+P / M
$$

where $M$ is the mill modulus or stiffness coefficient, and $P / M$ is the approximate value of mill stretch. 


\subsection{Forward Slip Equation}

The forward slip results from the difference between exit strip velocity and work roll velocity [14], and is defined as

$$
f=\frac{v_{\text {out }}-v_{r}}{v_{r}}
$$

where $v_{\text {out }}$ is the exit strip velocity, and $v_{r}$ is the work roll velocity.

When the exit strip velocity cannot be measured directly, the forward slip can be obtained by measuring strip tension and thickness [15].

A more useful model is described by Ford et al. in [16]. This model is often applied to the control system of cold mill, and is used in the work described in this paper. It is expressed as

$$
f=\frac{R^{\prime}}{h} \beta_{n}^{2}
$$

where $\sigma_{\text {in }}$ and $\sigma_{\text {out }}$ are the strip tension stresses at the stand input and output respectively, $\mu$ is the friction coefficient, and

$$
\beta_{n}=\frac{1}{2} \sqrt{\frac{H-h}{R^{\prime}}}-\frac{(H-h) k+\sigma_{i n} H-\sigma_{\text {out }} h}{4 k R^{\prime} \mu}
$$

In the case of cold rolling, $\mu$ is taken as the coefficient for sliding friction. In the case of hot rolling, $\mu$ is taken as the coefficient for sticking friction which is approximated by the empirical relationship given in Roberts [17] as

$$
\mu=0.00027 T_{F}-0.08
$$

where $T_{F}$ is the temperature of the strip in degrees Fahrenheit.

\section{Thickness Control System}

The average human response time is on the order of a quarter of a second, at the maximum rolling speed of a cold or foil mill, 8 meters of strip is produced. It is easy to see why AGC is an essential component of modern rolling mills. The comprehensive AGC system includes the following parts.

\subsection{Feedforward AGC (FF-AGC)}

The incoming gauge deviations measured with the thickness gauge at the entry of the mill are corrected by FF-AGC at the stand 1. FF-AGC compensates gauge errors very effectively due to material conditions and performance dynamics. FFAGC compensates even short term deviations in the entry gauge. It uses the entry thickness gauge to measure the irregular deviations in the unrolled strip and exerts an opposing effect on the strip.

The distance between the thickness gauge in the entry side and the roll gap is divided into several segments. The gauge errors are measured over the segment lengths and averaged speed. These segment are stored in a shift register and are transferred synchronously to the roll gap. The corresponding correction for the actuator is applied in time, which means under consideration of the response time of the actuator and the delay time of the thickness gauge, the associated gauge error is affected as it passes through the roll gap. 


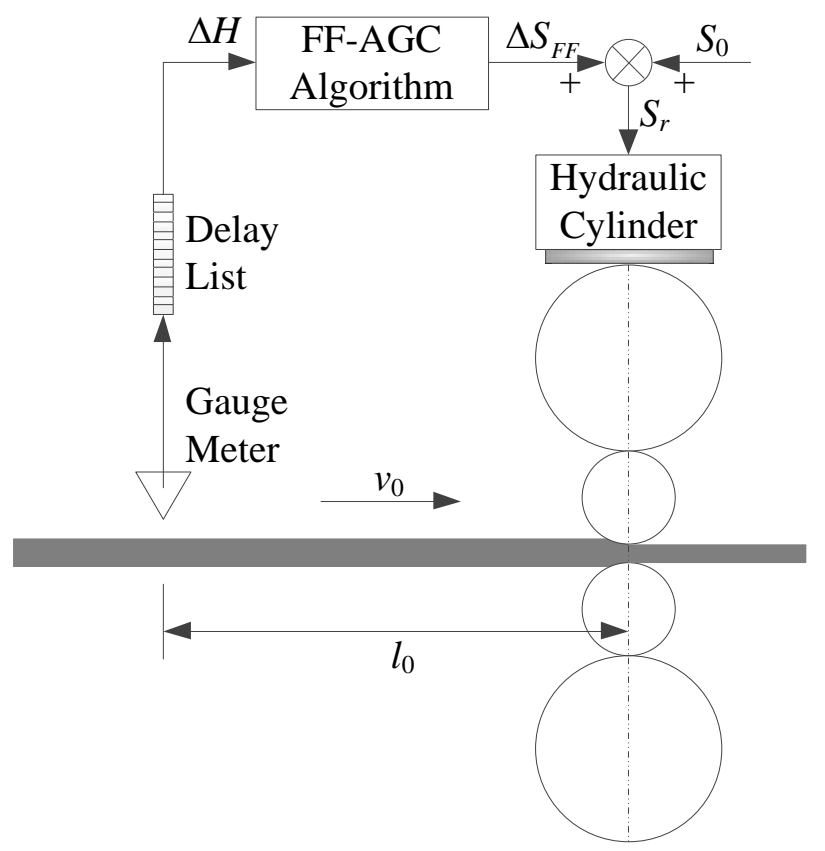

Figure 3. Simplified Schematic Diagram of FF-AGC

FF-AGC performs the tasks which are listed below and illustrated in Figure 3. FFAGC measures all entry thickness changes by the thickness gauge. As the thickness changes arrive, FF-AGC applies an open loop gauge offset to account for them.

The FF-AGC gauge correction is then computed to achieve the amount of expected delivery gauge from the expected equivalent entry gauge change. It can be calculated from

$$
\Delta S_{F F}=\frac{Q(1-K)}{M+Q(1-K)} \Delta H
$$

where $K$ is a compensation coefficient, $M$ is the mill modulus or stiffness coefficient, and $Q$ is the plastics coefficient of the rolled material.

The thickness value is removed from the delay list slightly before it arrives at the stand to allow the position regulator time to respond.

\subsection{Gaugemeter AGC (GM-AGC)}

GM-AGC uses roll gap and roll force measurements to control the exit gauge from a mill stand. Position sensors give measurements of the roll-position movements produced by hydraulic cylinders. Load sensors installed in the stand give measurements of the force transmitted through the mill housing. This control is based on the gaugemeter equation.

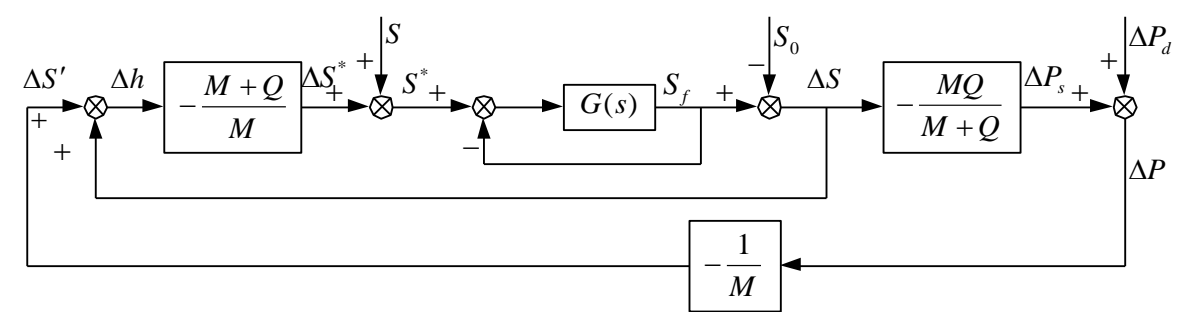

Figure 4. Applied GM-AGC System 
The applied GM-AGC is shown in Figure 4, where $G(s)$ is the integration transfer function of position controller, hydraulic system and mechanical system; $S, P, h$ are feedback values of the roll gap, roll force and exit thickness, respectively; $S_{L}$, $P_{L}, h_{L}$ are lock-on values of the roll gap, roll force and exit thickness, respectively; $\Delta S$ and $\Delta P$ are the deviations of the roll gap based on $S_{L}$ and the roll force based on $P_{L}$, respectively; $\Delta P_{S}$ and $\Delta P_{d}$ are the deviations caused by roll gap regulation and external disturbance, respectively; $\Delta S^{*}$ and $\Delta S^{\prime}$ are both the roll gap increments to eliminate the thickness deviations $\Delta h$, but the former is based on $S$ and the latter is based on $S_{L} ; S^{*}$ and $S_{f}$ are the roll gap set value and feedback value, respectively; $M$ and $Q$ are the mill and strip modulus, respectively.

GM-AGC uses the gaugemeter equation to estimate exit strip thickness at each stand [18]. The GM-AGC algorithm is expressed as

$$
\left\{\begin{array}{l}
\Delta h_{n}=\Delta S_{n}+\frac{\Delta P_{n}}{M} \\
\Delta S_{n+1}=\Delta S_{n}-\frac{M+Q}{M} \Delta h_{n}
\end{array}\right.
$$

where $n$ denotes the $n^{\text {th }}$ control cycle.

The mill modulus in the gaugemeter equation represents the transfer function that converts roll force to mill stretch. The mill stretch of each mill stand is divided into two components, the housing deformation and the deformation of bending and flattening. The housing deformation is a nonlinear function of the roll force which is derived from mill measurements without steel strip in the mill. The deformation of bending and flattening represents the mill stretch components that are dependent on the strip width. This component is a linear function of roll force and is based on mill structural dimensions. This value is modified to account for the strip width, roll diameters and roll types. The two deformation values combine to form the mill stretch which is added to the roll position to form the strip thickness.

When using the gaugemeter equation, care must be taken in converting the roll-force measurements into mill stretch. The GM-AGC works extremely well at controlling the gauge errors due to incoming strip changes that cause mill stretch. However, not all force changes are due to changes in incoming strip. Changes in the mill stand also produce force changes, which GM-AGC will, in fact, exaggerate. Therefore, reliable performance of the GM-AGC is required to compensate for these changes in the mill stand so that the GM-AGC will not react to them. These changes in the mill stand include the effect of roll heating, mill speed changes, roll bending, roll eccentricity, etc.

\subsection{Monitor AGC (M-AGC)}

M-AGC based on hydraulic roll gap control system is widely used in modern strip rolling mills [19-22]. In M-AGC system, the gauge meter at the delivery side of the stand 2 is used to measure strip gauge derivation, which can be controlled by adjusting roll gap. Because of the restriction of the mill structure and the requirement of the mill maintenance, the gauge meter is installed far from the mill.

According to control theory, the time delay in any feedback system reduces system stability and deteriorates dynamic characteristics, especially for the case of $\tau / T \geq 0.5$, where $\tau$ is the delay time, and $T$ is the time constant [23]. Because the inertia time constant $T$ of the hydraulic system is generally less than $50 \mathrm{~ms}$, the value of $\tau / T$ of the delivery stand is greater than 0.5 , and that of the upstream stands are much greater. 


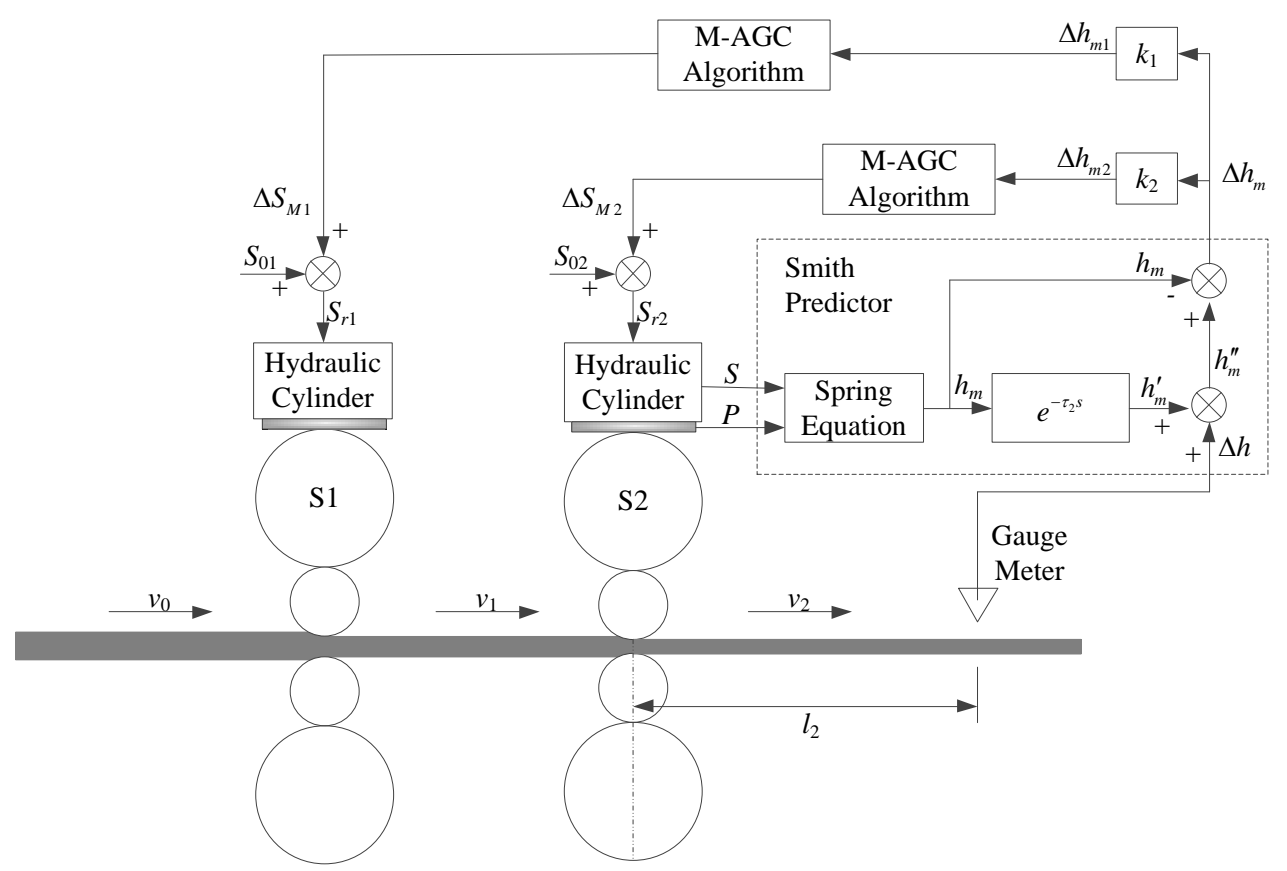

Figure 5. Schematic Diagram of the Complete Monitor AGC System

Plants with long time delay can often not be controlled effectively by using a simple PID (Proportional, Integral, and Derivative) controller. The main reason for this is that the additional phase lag contributed by the time delay tends to destabilize the closed loop system. The stability problem can be solved by decreasing the controller gain. However, in this case the response obtained is very sluggish [24].

The M-AGC process is a typical time delay process, for this kind of process the predictor can be chosen to be the classical Smith predictor (SP) [25]. The monitor AGC system with SP is shown in Figure 5, where $h_{m}$ is the calculated thickness, $h_{m}^{\prime}$ is the delayed calculated thickness, and $k_{1}$ and $k_{2}$ are distribution coefficients.

\subsection{Gap Compensations}

Gap compensations are open loop corrections to the gap position regulator for known effects that change the effective roll gap opening but are not directly measured by the gap position transducers. Gap position transducers measure the amount of cylinder extension. Although the measurements are very accurate, between position measurements and the actual gap opening are the backup roll chock and bearings, the backup roll diameter and the work roll diameter. When force is applied, the mill housing stretches, the backup roll necks bend, the roll surfaces flatten at the points of contact, the oil in the cylinder compresses and the backup roll moves off center in its bearing. As the mill stand speed increases the backup roll will become more centered in its bearing. As the rolls heat up they expand and their diameters increase. As the rolls wear their diameters decrease. The amount the rolls bend changes as roll bending force changes. The centerline gap changes as the side shift position changes. Force measurements (load cells) drift. In addition, the strip thickness changes when strip tension changes. 


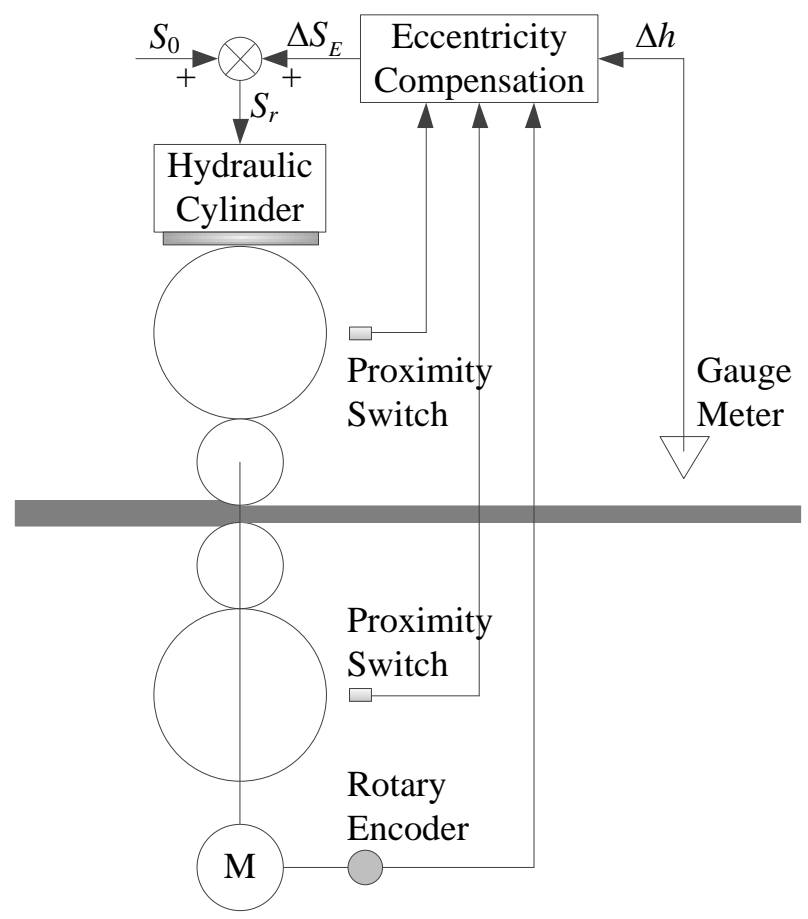

\section{Figure 6. Schematic Diagram of the Eccentricity Compensation}

Some of these effects are predictable and so an open loop estimate of the effect on the actual roll gap opening is calculated and used to establish the roll gap position. The mill zeroing procedure accounts for all the factors under the specific zeroing conditions of speed and force. The open loop calculations attempt to take care of the changes from the zeroing conditions. In general, factors that change slowly like roll wear and long term roll heating can be calculated by the setup models. Factors that change quickly are calculated by AGC functions.
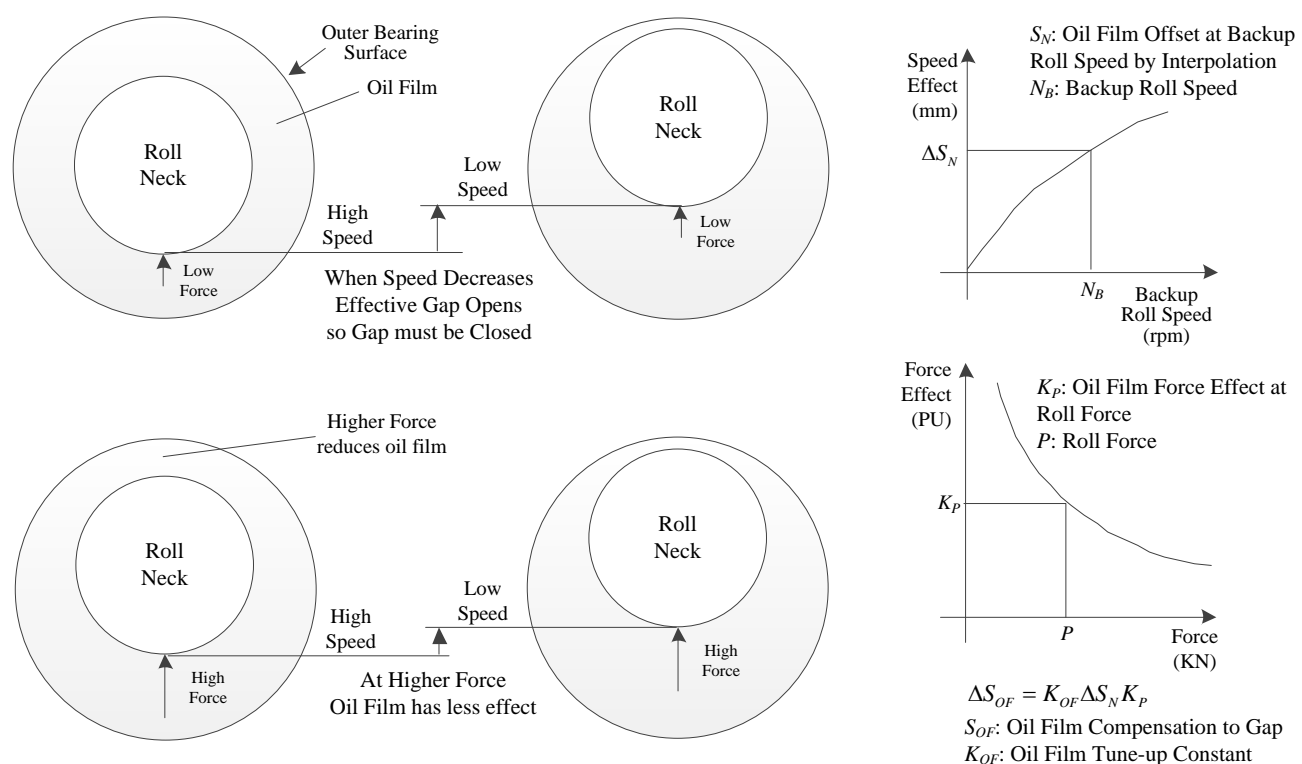

Figure 7. Oil Film Compensation of the Backup Roll Bearing

The backup roll eccentricity function compensates for backup roll diameter variations during a revolution (Figure 6). Compensation for oil compression in the gap 
cylinders and manual load cell zeroing are provided by the gap control function (Figure 7). All other effects that can be predicted by open loop calculations are grouped into the gap compensations AGC function.

\section{Practical Results}

Before we applied the new thickness control algorithm to the aluminum twin-stand cold rolling mill, an old control system including conventional AGC function had been running for about 5 years, but due to various reasons, the control effect was not ideal. To address the problems existing in the production process, we analyzed the sampled data, designed and implemented the comprehensive AGC system proposed in the paper. Our goal is to increase the thickness qualified rate by $2 \%$.

We didn't change the network structure of the control system. As shown in Figure 8, the basic automation mainly includes two Siemens controllers. One is S7-400 PLC (Programmable Logic Controller) with FM 458 module, the other is only S7-400 PLC. The FM 458 application module has been designed for high-performance closed-loop control and technological applications (e.g. Motion Control) which can be freely configured using CFC (Continuous Function Chart) and optionally SFC (Sequential Function Chart). It is designed for use in a SIMATIC S7-400 station. Together with two additional plug-in expansion modules, the FM 458 allows a large number of highdynamic applications, especially drive-related applications to be implemented. These include, for example, closed-loop torque, speed and position controls. The comprehensive AGC function is executed by the FM 458.

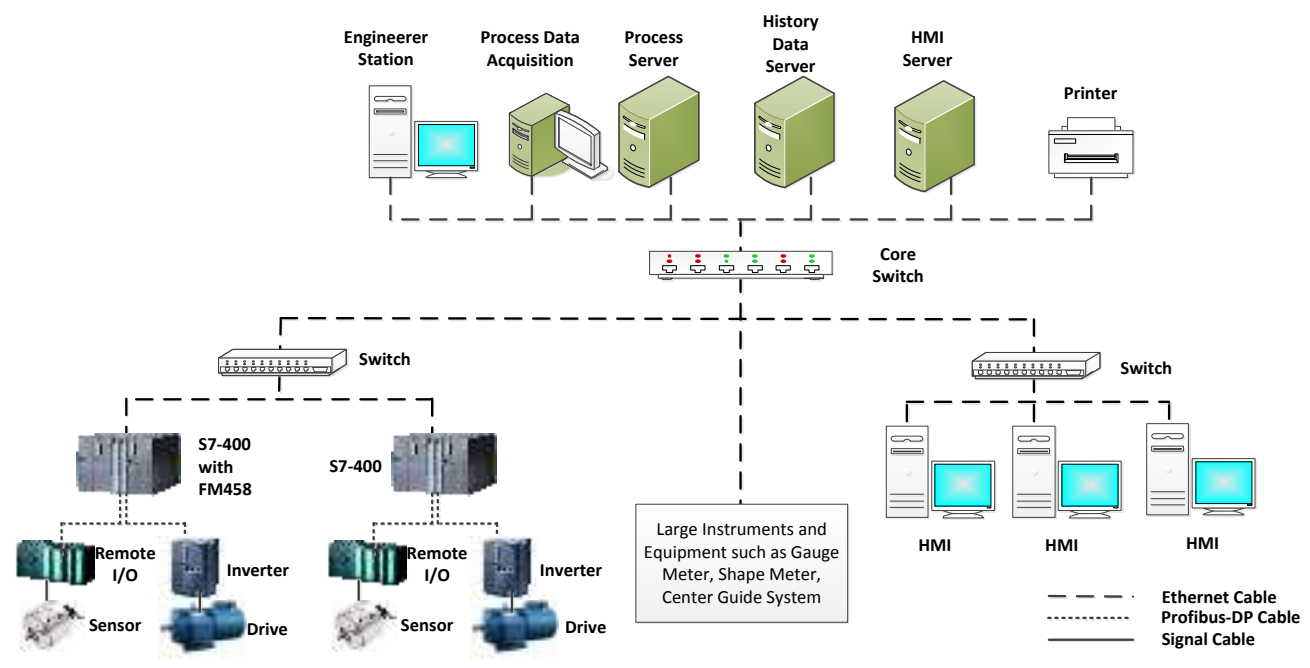

Figure 8. Network Structure of the Automation Control System 


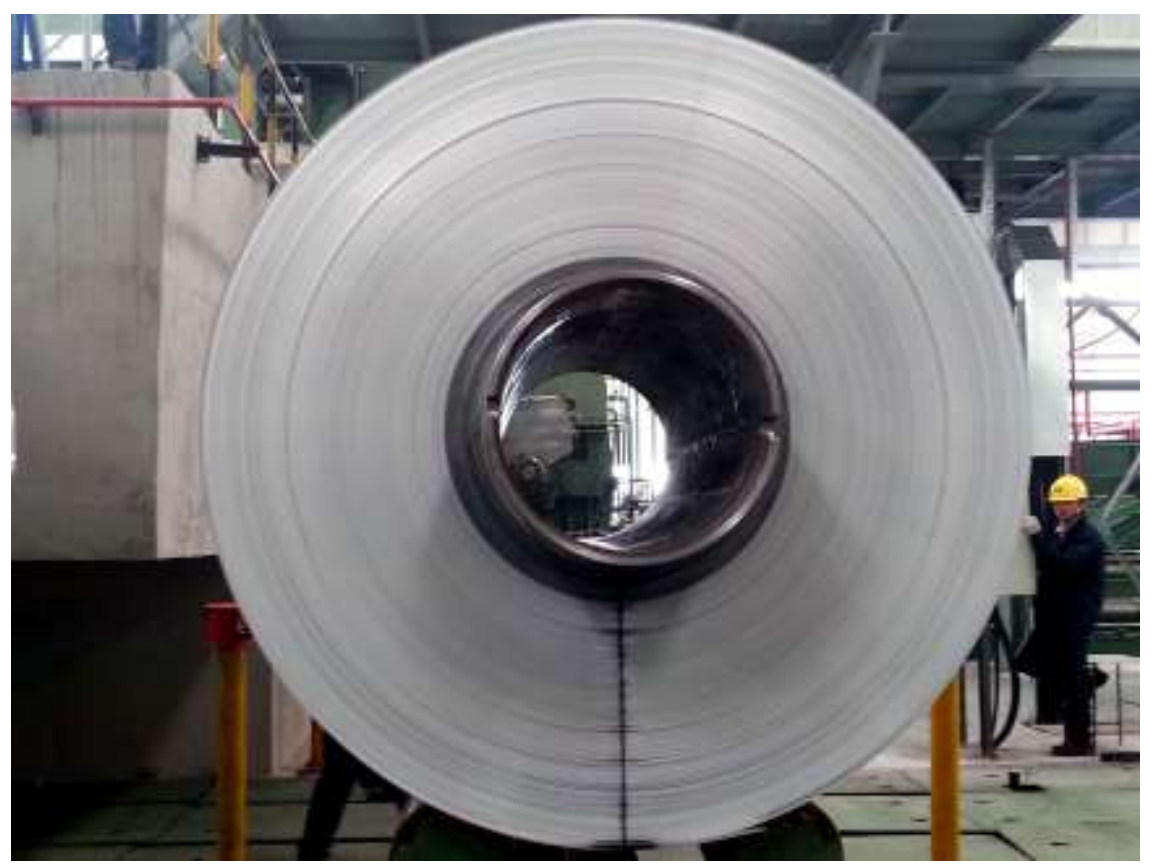

Figure 9. Rolled Aluminum Coil after System Revamp

In the rolling mill operating room, a set of operating table which is divided into the speed operating pulpit and the screwdown operating pulpit is set up according to the function, and the operation and monitoring HMI (Machine Interface Human) are provided. The HMI system is developed with SIEMENS's WINCC. The data exchange between operating pulpit and the main controller is via DP Profibus network, and the data exchange between TDC, PLC and HMI system is via Ethernet.
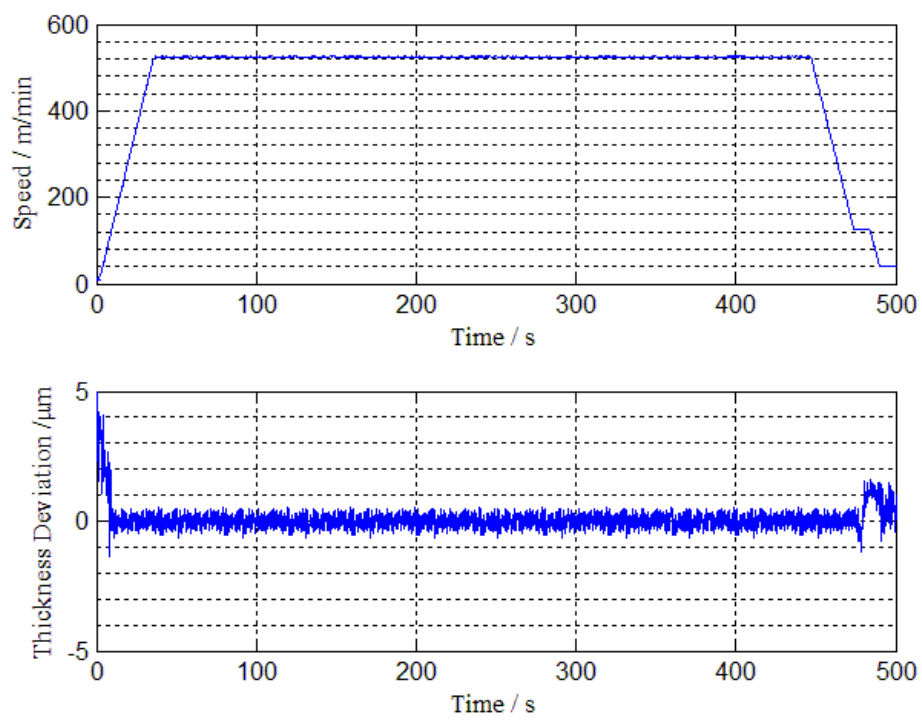

Figure 10. Rolled Aluminum Coil after System Revamp 

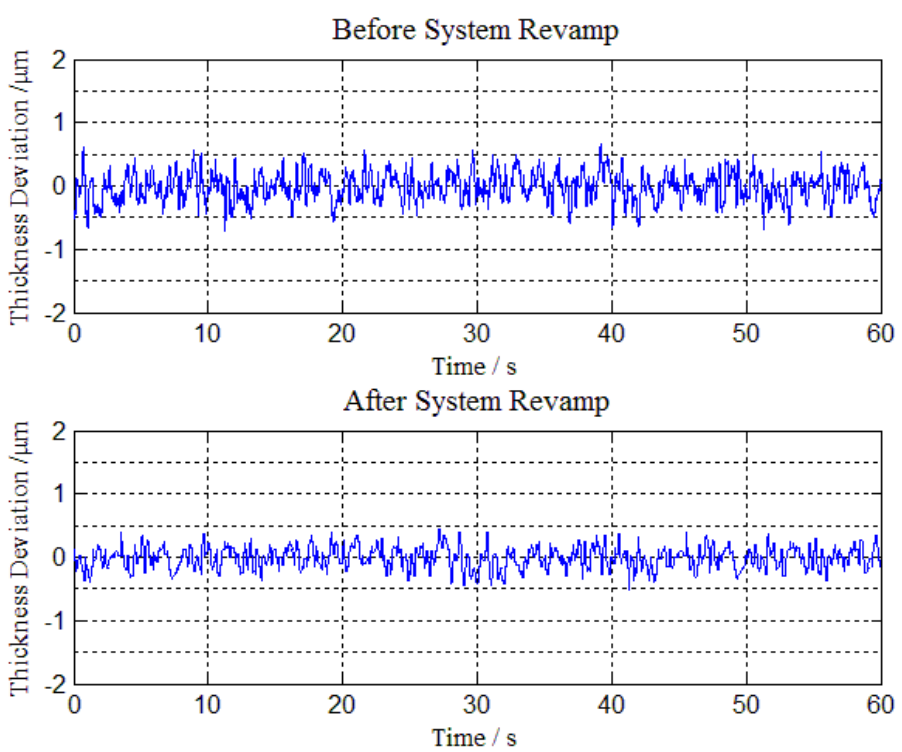

\section{Figure 11. Examples of Production Thickness Deviation before and after System Revamp}

According to the statistical data of two months, the ratio of the thickness deviation falling within $\pm 1 \%$ of the target thickness increased from $94.6 \%$ to $98.4 \%$. The system has surpassed its original performance targets. This success was not the result of a single factor, but of the thorough coordination of the total thickness control system. This included well-developed control strategies, structured design implementation, accurate simulation and calibration of the mill prior to rolling, as well as the availability of fully tested engineering analysis tools for the first day of rolling. The system was quickly brought online and has continued to enjoy very stable high performance as a result of these efforts. Figure 9 shows the rolled aluminum coil after system revamp. As for aluminum strips with the delivery thickness of $0.44 \mathrm{~mm}$, the control accuracy of the new AGC system and the comparison of the practical results is shown in Figure 10 and Figure 11, respectively. The acceleration pattern is also improved as the intermediate pause of acceleration which was necessary in the conventional control becomes unnecessary and the straight acceleration without pause becomes possible with the new system.

\section{Conclusion}

This paper has presented a comprehensive AGC algorithm for aluminum twinstand cold rolling mill. The performance of the new AGC system is much better than the old one, providing better thickness quality and more stable operation.

The new thickness control system described in this paper has been in full commercial operation since June, 2015. In the future the new system will be applied to some other rolling mills in China.

\section{Acknowledgements}

This work is partially supported by the Fundamental Research Funds for the Central Universities (FRF-TP-15-061A3), the National Natural Science Funds of China (51404021) and the Beijing Municipal Natural Science Foundation (3154035). 


\section{References}

[1] R. V. Singh, "Aluminum rolling: processes, principles and applications", Tata McGraw Hill Education Private Limited, New Delhi, India, (2011).

[2] H. W. Smith, "Dynamic control of a two-stand cold mill", Automatica, vol. 5, (1969), pp. 183-190.

[3] Aluminum Association, "Rolling Aluminum: from the mine through the mill", Aluminum Association, Waldorf, MD, USA, (2008).

[4] H. Y. Zhang, J. Sun, D. Zhang, S. Chen and X. Zhang, "Improved Smith prediction monitoring AGC system based on feedback-assisted iterative learning control”, J. Cent. South Univ., no. 21, (2014), pp. 3492-3497.

[5] F. Zhang, X. Xiang, B. Wang and X. Ren, "Virtual gauging system for hot strip mill", Sensors \& Transducers, vol. 172, no. 6, (2014), pp. 105-110.

[6] K. Durron and C. N. Groves, "Self-tuning control of a cold mill automatic gauge control system", Int. J. Control, vol. 65, no. 4, (1996), pp. 573-588.

[7] H. Katori, N. Yoshitani, T. Ueyama and S. Nyu, "Application of two-degree-of-freedom control system to automatic gauge control", Proceedings of American Control Conference, Chicago, USA, (1992).

[8] M. P. Groover, Author, "Fundamental of modern manufacturing: materials, processes, and systems", John Wiley \& Sons, Hoboken, USA, (2007).

[9] M. Kutz, Editor, "Mechanical engineers' handbook: manufacturing and management", John Wiley \& Sons, Hoboken, USA, (2006).

[10] W. I. Hameed and K. A. Mohamad, "Strip thickness control of cold rolling mill with roll eccentricity compensation by using fuzzy neural network", Engineering, no. 6, (2014), pp. 27-33

[11] C. T. de Á. Pires, H. C. Ferreira and R. M. Sales, "Adaptation for tandem cold mill models", Journal of Materials Processing Technology, no. 209, (2009), pp. 3592-3596.

[12] P. J. Reeve, A. F. MacAlister and T. S. Bilkhu, "Control, automation and the hot rolling of steel", Philosophical Transactions of the Royal Society A (Mathematical, Physical and Engineering Sciences), no. 357, (1999), pp. 1549-1571.

[13] F. Zhang, Y. Zhang, J. Hou and B. Wang, "Thickness control strategies of plate rolling mill", International Journal of Innovative Computing, Information and Control, vol. 11, no. 4, (2015), pp. 1227-1237.

[14] J. Pittner and M. A. Simaan, "An initial model for control of a tandem hot metal strip rolling process", IEEE Transactions on Industry Applications," vol. 46, no. 1, (2010), pp. 46-53.

[15] V. B. Ginzburg, "High-Quality Steel Rolling”, Marcel Dekker, New York, USA, (1993).

[16] H. Ford, E. F. Ellis and D. R. Bland, "Cold rolling with strip tension-Part I: A new approximate method of calculation and comparison with other methods", J. Iron Steel Inst., vol. 168, (1951), pp. $57-72$.

[17] W. L. Roberts, "Hot Rolling of Steel”, Marcel Dekker, New York, USA, (1983).

[18] G. Hwang, H. S. Ahn, D. H. Kim, T. W. Yoon, S. R. Oh and K. B. Kim, "Design of a robust thickness controller for a single-stand cold rolling mill", Proceedings of the 1996 IEEE International Conference on Control Applications, Dearborn, USA, (1996), pp. 468-473.

[19] H. Dyja, J. Markowski and D. Soinski, "Asymmetry of the roll gap as a factor improved work of the hydraulic gauge control in the plate rolling mill", Journal of Materials Processing Technology, no. 60, (1996), pp. 73-80.

[20] S. Khosravi, A. Afshar and F. Barazandeh, "Design of a novel fuzzy adaptive PI controller for monitor hydraulic AGC system of cold rolling mill", 2011 2nd International Conference on Instrumentation Control and Automation, Bandung, Indonesia, (2011).

[21] W. Y. Chien, H. H. Cheng, C. S. Yi and M. C. Chang, "A strategy to monitor AGC in consideration of rolling force distribution", China Steel Technical Report, no. 26, (2013), pp. 18-21.

[22] D. Li, J. Liu, S. Tan, X. Yu and C. Zhang, "A new monitor-AGC system in hot continues rolling", Proceedings of the 33rd Chinese Control Conference, Nanjing, China, (2014).

[23] D. Zhang, H. Zhang, T. Sun and X. Li, "Monitor automatic gauge control strategy with a Smith predictor for steel strip rolling", Journal of University of Science and Technology Beijing, vol. 15, no. 6, (2008), pp. 827-832.

[24] I. Kaya, "Autotuning of a new PI-PD Smith predictor based on time domain specifications", ISA Transactions, no. 42, (2003), pp. 559-575.

[25] O. J. M. Smith, "Closed control of loops with dead time", Chem. Eng. Prog., no. 53, (1957), pp. 217 219. 